Journal of Social and Development Sciences

Vol. 4, No. 7, pp. 325-331, July 2013 (ISSN 2221-1152)

\title{
An analysis of Factors Contributing to the Increase of Tobacco Consumption in Bangladesh despite Restrictive Anti-Smoking Policies
}

\author{
*Ahmed Tariful Mursalin¹, 2Khan Muhammad Saqiful Alam, ${ }^{3}$ Iftekhar Mahfuz \\ ${ }^{1}$ University of Alberta, Alberta, Canada \\ ${ }^{2}$ North South University, Dhaka, Bangladesh \\ 3Independent University, Bangladesh \\ *mursalin@ualberta.ca
}

\begin{abstract}
This paper examines an emerging issue rising up in a developing economy like Bangladesh "Indirect Marketing of Tobacco Products". This indirect marketing activity is currently moving under the radar of various government monitoring cells. As a result, there is an increase in the number of both underage and legal smokers in the country. The health risks due to the consumptions of the tobacco related products are now one of the widely discussed topics. Worldwide tobacco products are highly discouraged by both medical experts and governments. Governments in both developed and developing countries heavily regulated "Above the Line Marketing Activities" (ATL) utilized by the tobacco companies. Therefore, tobacco companies now employ "Below the Line Marketing Activities" to promote their products. Such activities include point of sale merchandizing, retailer advocacy and various discounting mechanisms. Tobacco companies in Bangladesh also employ such activities to advertise their brand portfolio. Although from a legal point of view, these marketing efforts are only employed to encourage the consumers to switch brands. However, the ripple effect of such marketing activities, growth of cigarette selling outlets (side effects of socio-economic condition of Bangladesh) and inefficiency in rigorous implementation of tobacco laws are encouraging underage/matured population of the country to become occasional smokers, who later on develop habitual smoking despite the restrictive anti-smoking laws. In this research, primary analysis is done through set questionnaires in the Sample Retail Universe (556 retailers randomly chosen from various parts of Bangladesh) along with "Retail Audit" data used to obtain the industry trend analysis. A strong positive correlation can be observed between the industry growth and the different parameters used in the study such as effects of Below the Line Marketing Activity, growth of cigarette selling retail universe and weak implementation anti-smoking policies by the government. The research gives us an insight into the true picture of tobacco industry's surge with respect to the tobacco consumer behavior and the remedies needed to close the gap.
\end{abstract}

Keywords: Tobacco, Consumption, Anti Smoking Policies

\section{Introduction}

An understanding of patterns of smoking across the nation is crucial before effective policies can be framed to control tobacco use (Goel and Nelson, 2004). While in the developed countries smoking is on the declining trend, but due to the socio-economic condition of the developing countries the same trend cannot be observed. Bangladesh too as a developing nation is facing severe difficulty in reducing the number of smokers. Although a number of anti-smoking, policies are being implemented in these parts of the world. However, the effectiveness of such campaigns has not been taken into the account. This research aims to look at the insight of the effectiveness of these restrictions together with the different forms of marketing campaigns the tobacco industry is undertaking using industry trend analysis method. The socio-economic condition of Bangladesh is also another major factor leading to the growth of the Tobacco Industry and consumers. All the factors need to be both qualitatively and quantitatively measured to find the underlying causes of the industry non-decline trend, so that a remedy can be developed. 


\section{Literature Review}

Public concern about the health effects of smoking has prompted a number of countries to adopt policies designed to reduce tobacco use (Nelson, 2003). It can be said that tobacco usage is one of the major causes for lower mortality. The consumption is somewhat stagnated in the developed worldhowever a major concern still underlies regarding tobacco consumption in the third world despite the same level of restrictive policies (FAO, 2003). Bangladesh, a developing country in South Asia has a large consumer base for tobacco consumption in different forms such as tobacco leaf oral consumption, cigarettes, bidi etc. After 2004, the first anti-tobacco policy was enacted by the Government of People's Republic of Bangladesh in order to discourage consumers' tobacco intake frequency. However, most restrictive policies are most rigorously applied to the cigarette industry ("Tobacco Control Law", 2004). Notable players in the industry are British American Tobacco Bangladesh, Dhaka Tobacco Industry and AbulKhayer Tobacco Company. Almost 15 companies compete in the cigarette market (Efroymson et al., 2001).Other forms of tobacco products especially consumed orally are not facing strict controls.

The policy can be subdivided into two groups:

- Price Mechanism: Taxes and levies imposed annually at an increasing rate thus raising the price slabs in the process of each segment. The tax mechanism reduces the demand driven approach by curtailing the purchasing power of the consumers. Higher price allows for overall reduction in pack consumption (Nelson, 2003).

- Non Price Mechanism: Several Non Price Mechanisms have been adapted to discourage smoking.

Such mechanisms are:

Advertising Bans are the most common medium to discourage tobacco consumption

- Bans on the medium on which the advertisement of the tobacco appears TV, radio, newspaper etc.

- Bans on the locations such billboards, posters etc.

- Bans on advertising the product to certain audiences (minors)

- Advertising and content needs prior approval from the authority, sponsorship to various sporting events, cultural events etc. or display of tobacco identifying information on non-tobacco products (Nelson, 2003)

Restrictions on Sales and Distribution of Tobacco Products

- Prohibition of sales of tobacco products to minors

- Proof of identity required for the sale and distribution of tobacco products for recognizing that the consumer is adult.

Regulation of Tobacco Control and Packaging

- Health warnings required on tobacco packages or advertisement of tobacco products.

- The amount of tar, nicotine or other constituents in cigarette must be displayed on the packet of the tobacco product (Nelson, 2003)

Tobacco Restriction Policies in Bangladesh: Although tobacco restriction policies are generalized to an extent in the context of developed country scenario, Bangladesh too follows similar guidelines in its effort to reduce tobacco consumption. Both Price and Non-price mechanisms are simultaneously implemented. (Bangladesh Tobacco Law, 2004) The types of Price and Non price mechanisms prevailing in Bangladesh are:

- Annual increase of corporate tax and VAT increasing the price of Cigarettes each year.

- Ban on Tobacco Product Advertising print and electronic media including displaying the advertisement in films, video tapes, internet and television, airing on radio or printing in newspapers, books, magazines, handbills or any other printed papers published in Bangladesh (not restricted to point of sale advertising POSM (Point of Sales Merchandizing)) 
- Banning smoking in public offices, public transports and roads.

- Prohibition of tobacco products being distributed for free as a sample marketing campaign by tobacco companies.

- Prohibition of taking part in any incentive promotions such as lottery, free gifts etc.

- Mandatory health warning messages are placed on each pack of the cigarette packs (Bangladesh Tobacco Law, 2004).

Gap in the Current Restrictive Scenario: All of the above policies basically adhere to the basic procedures to reduce cigarette smoking. However, the companies operating in Bangladeshi Tobacco Industry have adapted to using Below the Line Marketing Activities to promote their products. Such activities are proving to be very effective to increase the tobacco sales off-setting the proposed decline of the tobacco consumption behavior. Furthermore, the weak implementation of such activities has enabled certain ways to bypass the restrictions. For example: In Bangladesh, the cigarette posters allowed for advertisement in the point of sales are regulated by the authority to be off a certain size to limit the visibility of the advertised product. However, the lack of implementation and monitoring of the policies in the field level by the authority make it easy for the tobacco companies to break the law. This phenomenon is further facilitated by the rapidly growing cigarette selling retail universe. The proposed research aims to discuss the variance between volumes of cigarettes sold by the companies and the effectiveness of the restrictive policies so far implemented. Therefore, the existing gap willprovide us an opportunity to comprehensively comprehend the broader spectrum of the problem.

\section{Methodology}

The research will be an exploratory study of why despite restrictive policies the tobacco consumption is not reducing as per the expectation of the society (Zikmund et al., 2012). Before going into the research, we first analyzed the industry trend. The data is gathered from Retail Audit Figures (A market research conducted monthly by British American Tobacco Bangladesh through Nielsen to understand its brand availability and off-take). This secondary study gave us the needed reasons to look into different literatures relating tobacco and develop a model to find out the underlying gap and the causes of the behavior (Bryman and Bell, 2007). Both qualitative and quantitative methods are taken into consideration of the research.Qualitative will consist of open ended interviews of sample retailer ( 556 retailers from different parts of Bangladesh, expert opinion from an employee of British American Tobacco Bangladesh, existing anti-tobaccotobacco laws and other publications (Berg, 2004). Quantitative research will be based upon primary structured interviews of the retailers and secondary Retail Audit Analysis (Nielsen, 2003)

\section{Background Scenario}

Socioeconomic Condition of Bangladesh: Bangladesh, with a population of 144 million people, is one of the poorest countries in the world, with a promise of emergence in the form of economic drive and growth by utilization of the enormous labor. However, Bangladesh has a low literacy rate, estimated at $61.3 \%$ for males and $52.2 \%$ for females in 2010 (Cia.gov, n.d.). The agriculture based economy is quite prevalent in rural sectors of Bangladesh, residence to majority of the Bangladeshis. It has become visible that most of the studies on socio-economic, particularly poverty, in Bangladesh are concerned with measurement of poverty by estimating income and nutritional deprivations. Basically, the tobacco consumption is more of a habitual condition due to different cultural factors. Traditionally this habit is passed down in generations from elders to the younger generations. Further, tobacco consumption behavior is fueled by being a form of entertainment in the rural areas. Co-existing with extreme poverty is a thriving tobacco industry. The tobacco products are quite the part of the daily consumption for almost 38.7 million smokers (Nationmaster.com, 2003). Tobacco consumption exacerbates the effects of poverty and causes significant deterioration in the living standard of the rural and semi-urban dwellers. On average, the poor in Bangladesh spend most of their money on food and other essential goods, yet are still unable to provide even the basic necessities for their families. However, despite the high level of poverty in Bangladesh, smoking rates are relatively high. Men aged 35-49 years have the highest smoking prevalence at $70.3 \%$ and smoking prevalence is the highest among the poorest.Cigarettes are the most expensive form of Tobacco products followed by bidis. The economic condition coupled with a culture to spend leisure activities in rural tea stalls make cigarette a 
medium of stress reliever.The typical male cigarette smoker spends over five times as much on cigarettes as the per capita expenditure on house rent, 18 times as much as for health, and 20 times as much as for education (Effroymson et al., 2001).

Linking Socio Economic Condition with Tobacco Retail Industry: An economic theory exists which shows that availability is directly correlated to inducing demands. Due to the poor economic condition of rural dwelling people, setting up business withhigh start-up cost is not possible for them. The startup capital needed to start a cigarette selling retail shop is very low. According to the primary research, average startup capital constitutes 2000 taka on average. Every minute in whole of Bangladesh 11-20 outlets are started by the low margin based entrepreneurs; this has been a major cause of increase in tobacco consumption despite restrictive advertising. Both direct and indirect distribution methods are employed by the tobacco companies to ensure that their brands are placed in each of these shops. Direct distribution involves third party/company distributors to ensure placement of the products through sales representatives. However, the retail universe is 7-8 million shops and direct distribution model is not a cost effective option due to increasing transportation cost. Cost coverage ratio model is used in order to determine the distribution model which below. Therefore, marginal retailers buy small quantities from large wholesalers in different areas. Thus, cigarette is available in all the corners of the land. Thus the sheer availability of cigarettes especially the low segment brands takes up a certain space in the cognitive mind of the already and potential smokers. So in a way the consumers get more inclined towards smoking.

The Secondary Industry Trend Analysis (Retail Audit Figures): Even with the restrictive law, tobacco consumption is not reducing rather is fairly stable as shown in an industry analysis chart of Tobacco Industry as a whole.

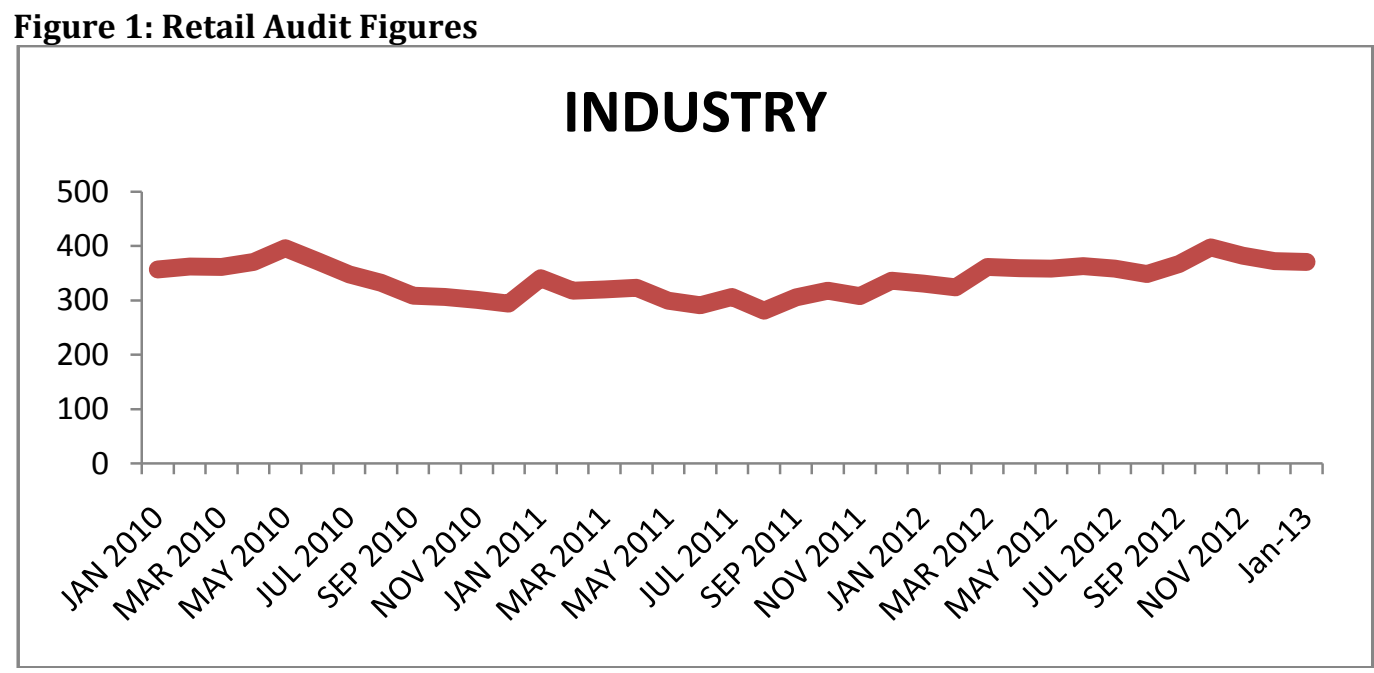

Source: Retail Audit Jan 2013

In the table above, it can be seen that over the past 3 years the industry remained in a very stable position. It shows that the restrictive laws do not have any effect in the off-take volume in the cigarette industry. Although a significant growth cannot be observed in the trend analysis, still a relative speculation is present that likely future growth can sprout from the baseline. According, to the BATB the industry of tobacco is not growing as a whole rather the shift is observed from the bidi industry to the cigarette industry. The significant factor is the emergence of TK 1 segment known as the Low Segment. This segment is pulling the bidi smoker to switch to cigarettes through increased Below the Line Marketing Activities by the Cigarette Industry using POSM (Point of Sales Merchandizing), Retailer Engagement, Consumer Engagement and other activities.

The Emergence of Low Segment Cigarette Analysis: The low segment brands formerly known as the (Very Low Segment) is a major cause of industry not dropping in volume sales despite the annual tax imposition by 
the government. These kinds of brands initially operated at Tk.1 segment before a new ruling in March 2012 to move the prices uptoTk 1.5. Now this segment is a key to hold the market share for each of the main players in the Tobacco Industry. The market leader British American Tobacco Bangladesh holding 36.7-37.1 market shares always plays a battle with Dhaka Tobacco (DTI) with leadership. Despite DTI falling behind in most of the 90s turned its fate around 2005 when the tax levy was decided to be imposed in all of the brands increasing the price slab. Such notable examples were Star (BATB) and Navy (DTI). Thus, in order to hold the market share DTI introduced Sheikh at TK 1. BATB was reluctant to operate in this level as the profit margin was very low (EAT). The grand success of this new initiation allowed DTI to slowly crawl its way to become the market leader. Large segment of consumers previously Bidi smokers came to this segment due to massive campaigns conducted by the cigarette industry. Therefore this has become a common trend, whenever additional Tax is imposed to raise the price slab of each segment. The new brands emerge at the lower segment. The low industry trend is shown below clearly implying that industry is growing.

\section{Figure 2: Low industry trend}

\section{Low Industry}

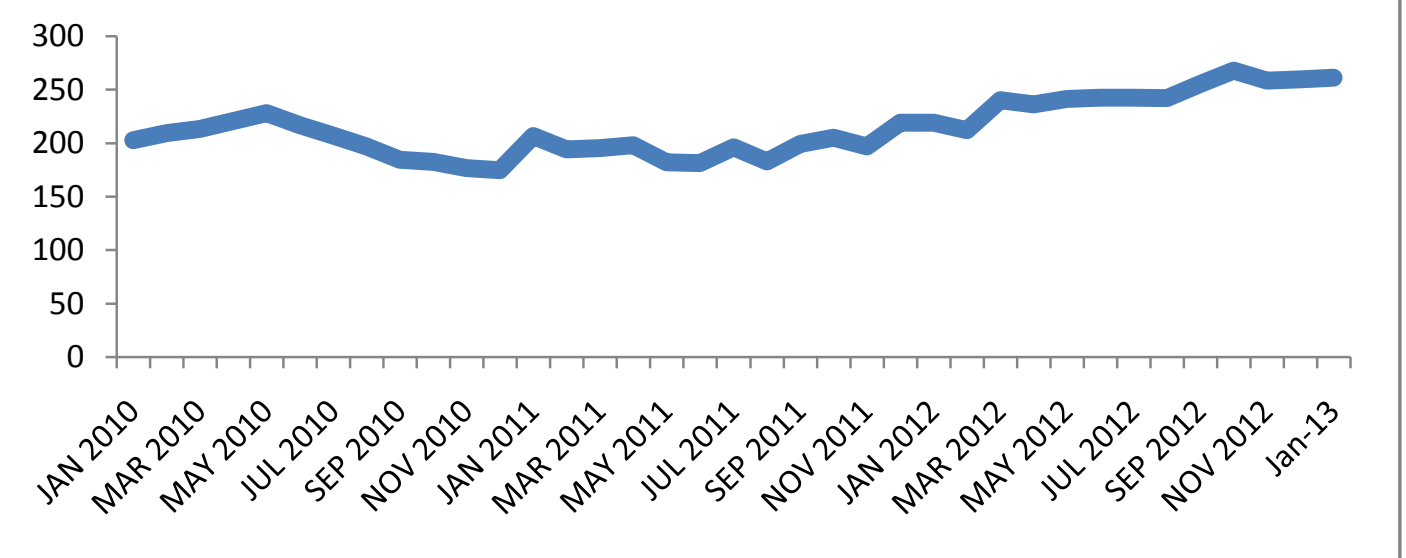

Source Retail Audit Jan 2013

Below the Line Marketing Activity: The ban of advertising of tobacco products in most of the mediums forced the companies in the tobacco industry to take up another marketing approach, which is known as Below the Line Marketing Activity. The marketing efforts are significantly increased in the cigarette selling outlets. Consumer engagement to Adult Smoking Units (18-30 years of age ASU 30) targeted segmentation is highly prioritized through brand representative at the beginning of each campaign. The retailers are also the primary customer of the tobacco industry in order to advocate the respective targeted brands irrespective of the others. This is a highly sought after mechanism as through research it can be seen that consumers are highly influenced by the advocacy of the retailers. The trial run enables consumers to switch the brands (ASU 30). Brand switching is the primary goal of the tobacco companies. Now the switching of brands among the targeted consumers does not cause the whole industry to shift up. However, all these marketing ploys have a ripple effect that encourages non-smokers to develop smoking habits. Therefore, the industry by volume increases. POSM (Point of Sales Merchandizing) have impact in changing the perception of the consumers and non-smokers to begin a preference towards a particular brand and/or develop smoking preference as a whole. The diagram below shows the different aspects of BTL activities. 
Figure 3: Different aspects of BTL activities

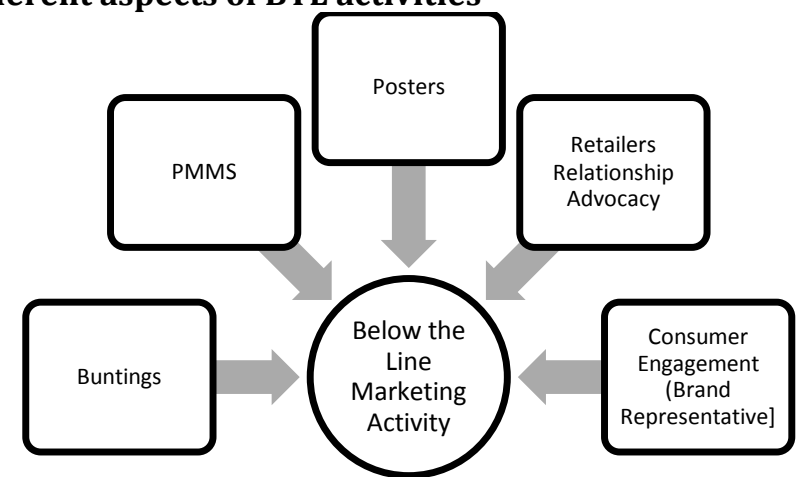

- Plannograms- blank packets fixed into the cigarette selling shops.

- Poster- These are traditional pictorial advertising of different brands placed inside the cigarette selling shops.

- Buntings- These are threaded small sized posters.

- PMMs- Product Merchandizing Material provided by the tobacco companies in forms of boxes, which can be used as a street kiosk.

- Retailers Relationship Advocacy- the Tobacco Company often runs promotions to retailers to off-take their products to the consumers. Often they provide target sales to the retailers based upon achievement a monetary incentive are provided

- Consumer Engagement (ASU 30) - A marketing ploy used by the tobacco companies to target smokers of above 18 but below 30. These consumers are more susceptible to change their brand preference. Therefore, through brand representatives they are constantly advertised one-to-one in local tea stalls.

Quantitative Analysis Relating the Below The Line Activities to the Off-take Volume of cigarettes: Now through our primary research, we have set the independent variable as the number of BTL marketing cycles engaging each retailer and dependent variable as the additional number cigarettes sold per outlet as the direct result of the marketing activity.

Hypothesis Testing

H0: Below the Line Marketing Activity of Cigarette have not caused the off-take volume of cigarettes to increase per retail shop.

H1: Below the line marketing activity of Cigarettes have caused the off-take volume of cigarettes to increase per retail shop.

A strong correlation can be observed in the primary research conducted with the retailers the number of campaigns with consumption behavior model

Table 1: Correlations

\begin{tabular}{lccc}
\hline & & BTL Campaigns & Cigarette Sales \\
\hline \multirow{3}{*}{ BTL Campaigns } & Spearman Correlation & 1 & $0.42^{* *}$ \\
& Sig. (1-tailed) & & .000 \\
& N & 556 & 556 \\
Cigarette Sales & Spearman Correlation & $0.42^{* *}$ & 1 \\
& Sig. (1-tailed) & .000 & \\
& $\mathrm{~N}$ & 556 & 556 \\
\hline
\end{tabular}

**. Correlation is significant at the 0.01 level (2-tailed).

Through Spearmen's Correlation model we have found non-parametric model. Therefore, the Null Hypothesis can be rejected, implying an existing relationship of BTL activities to increase in off-take volume of cigarettes. To further verify the result, we have taken into account the significance level of the standard error, which is very low and thus the relationship can be deemed reliable. 
Table 2: Regression Results

\begin{tabular}{ll}
\hline Regression Components & Results \\
\hline Dependent Variable & Sales of Cigarettes (in thousand) \\
Independent Variable & BTL Activities (per month) \\
$\mathrm{R}^{2}$ & 0.89 \\
ANOVA (Significance) & $0.00^{* *}$ \\
Constant & 28.32 \\
Beta & 0.031 \\
T-stats & $0.00^{* *}$ \\
Equation & Sales $=0.031$ BTL Activities +28.32 \\
\hline
\end{tabular}

$\mathrm{R}$ square at 0.89 is relatively high proving the correlation is a reliable model. ANOVA at $(0.00)$ and T tests also at 0.00 proves the model to be fairly accurate in its result. Beta $(0.031)$ means that there is a positive causality between the dependent and the independent variable, and that with one extra BTL activity an increase of 31 cigarettes sold on average from each retail shop.

\section{Conclusion}

Therefore, it can be concluded that only restricting the Above the Line marketing and increasing Corporate Taxes annually for tobacco companies are notenough for reducing the consumption of the cigarettes. Also below the line marketing activity should be restricted. A regulation can be proposed to the tobacco companies to restrict the number of BTL cycles per year. ATL marketing activities regulation should also be properly monitored so that irregularities do not take place such as selling cigarettes to minors, not adhering to the laws of merchandizing etc. The rapid growth of cigarette selling retail universe is making quitedifficult for the authorityto impose proper regulation. Therefore, in this case massive awareness campaign should be developed to discourage the growing cigarette selling retailers to abandon selling cigarettes in their shops. All these recommendations are definitely difficult for a country like Bangladesh to implement but in order to preserve the health of the future generations taking such steps are quite vital as we believe that the growth and prosperity of Bangladesh lies in the productivity and health of its workforce.

\section{References}

Berg, B. L. (2004). Qualitative research methods for the social sciences (Vol. 5). Boston: Pearson.

Bryman, A. \& Bell, E. (2007). Business research methods. Oxford University Press, USA.

Cia.gov (n.d.) CIA - The World Factbook. [online] Available at: https://www.cia.gov/library/publications/theworld-factbook/geos/bg.html [Accessed: 15 April 2013].

Efroymson, D., Ahmed, S., Townsend, J., Alam, S. M., Dey, A. R., Saha, R. \& Rahman, O. (2001). Hungry for tobacco: an analysis of the economic impact of tobacco consumption on the poor in Bangladesh. Tobacco control, 10(3), 212-217.

Fao.org. (2003). FAO : Higher world tobacco use expected by 2010 - growth rate slowing down. [online] Available at: http://www.fao.org/english/newsroom/news/2003/26919-en.html [Accessed: 3 May 2013].

Goel, R. K., \& Nelson, M. A. (2004). International patterns of cigarette smoking and global antismoking policies. Journal of Economics and Finance, 28(3), 382-394.

Nationmaster.com. (2003). Health in Bangladesh: Statistics (175 seats available). [online] Available at: http://www.nationmaster.com/country/bg-bangladesh/hea-health [Accessed: 2 May 2013]

Nelson, J. P. (2003). Youth smoking prevalence in developing countries: effect of advertising bans. Applied Economics Letters, 10(13), 805-811.

Tobaccocontrollaws.org. (2004). Bangladesh Details - Tobacco Control Laws. [online] Available at: http://www.tobaccocontrollaws.org/legislation/country/bangladesh/summary [Accessed: 17 April 2013].

Zikmund, W. G., Carr, J. C. \& Griffin, M. (2012). Business Research Methods (with Qualtrics Printed Access Card). South-Western Pub. 